Supplementary Information for:

\title{
Dangling-End Double Networks: Tapping Hidden Toughness in Highly Swollen Thermoplastic Elastomer Hydrogels
}

Chen Guo $^{a}$, Jackson T. Lewis ${ }^{a}$, Vincent F. Scalfani ${ }^{b}$, Miriah M. Schwartz $^{a}$ and Travis S. Bailey ${ }^{a}$

${ }^{a}$ Department of Chemical \& Biological Engineering, Colorado State University, Fort Collins, Colorado, 80523, United States. E-mail: travis.bailey@colostate.edu

${ }^{b}$ University Libraries, Rodgers Library for Science and Engineering, University of Alabama, Tuscaloosa, Alabama 35487, United States.

Contents:

(1) ${ }^{1} \mathrm{H}-\mathrm{NMR}$ spectrum of SO-H

(2) ${ }^{1} \mathrm{H}$-NMR spectrum of SO-Ms

(3) ${ }^{1} \mathrm{H}-\mathrm{NMR}$ spectrum of SO-azide

(4) ${ }^{1} \mathrm{H}$-NMR spectrum of SO-alkyne

(5) FTIR result for SO-azide

(6) SEC overlay of SO-H, SO-Ms, SO-azide, and SO-alkyne

(7) SAXS data for SO-H, 49 mol\% SOS, blends A, B, C, and D

(8) SEC of SOS Fractionation Sequence

(9) SEC Comparision of SO-H/SOS blends pre- and post application of the hot press

(10) Frequency sweep results (elastic shear moduli) for samples A1 - D1, baseline SO-H/SOS hydrogels of 4.1 and $20.3 \mathrm{~mol} \%$ SOS, and a catalyst control sample

(11) Unconfined compression for samples A1 - D1, and a catalyst control sample

(12) Sample Identification History

(13) References 
(1) ${ }^{1} \mathrm{H}-\mathrm{NMR}$ spectrum of $\mathrm{SO}-\mathrm{H}$

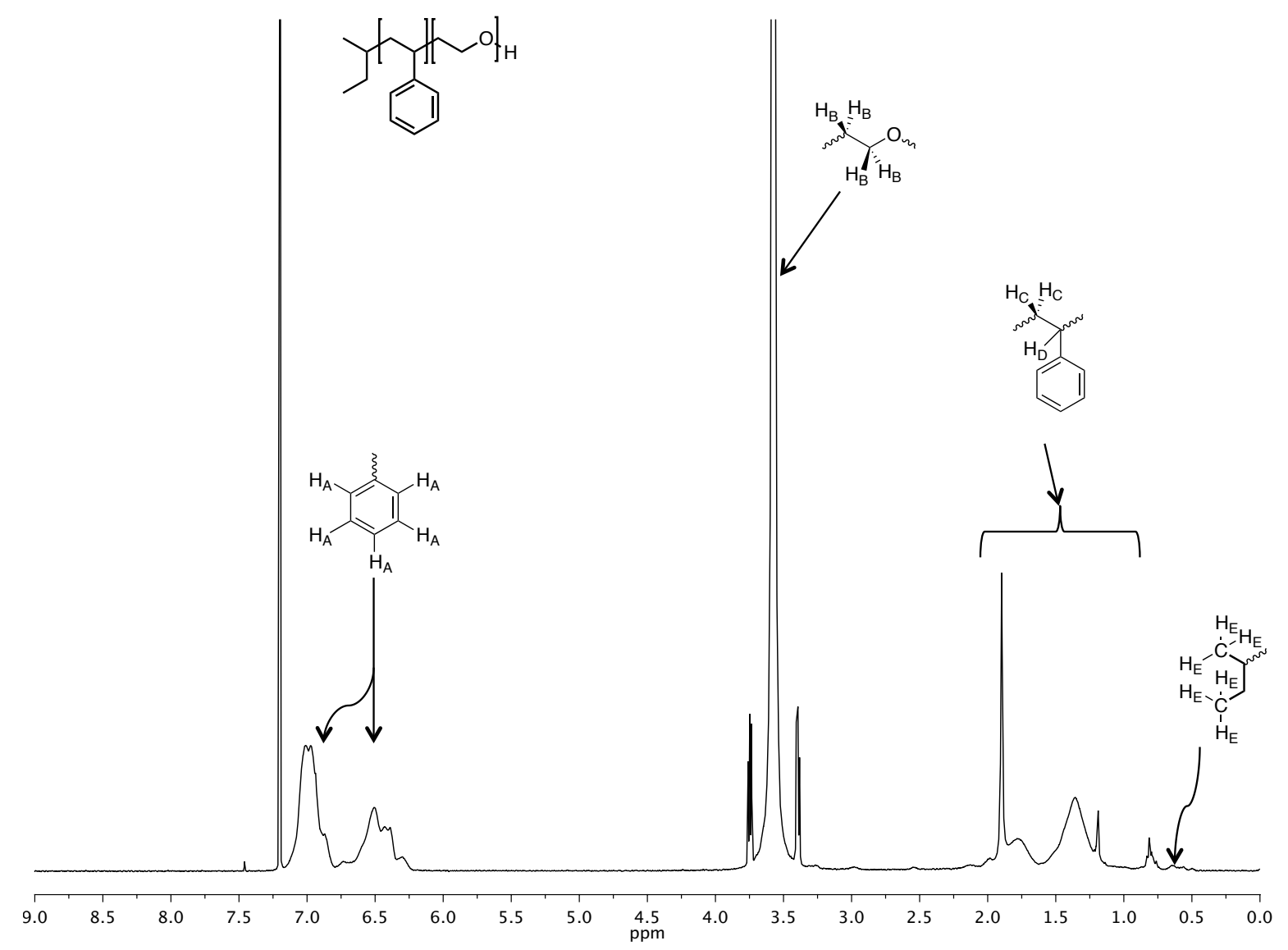

Figure S1. ${ }^{1}$ H-NMR spectrum of SO-H diblock copolymer. The SOS triblock copolymer, SO-azide diblock copolymer, and SO-alkyne diblock copolymer were all generated from the above parent diblock copolymer molecule. 
(2) ${ }^{1} \mathrm{H}-\mathrm{NMR}$ spectrum of SO-Ms

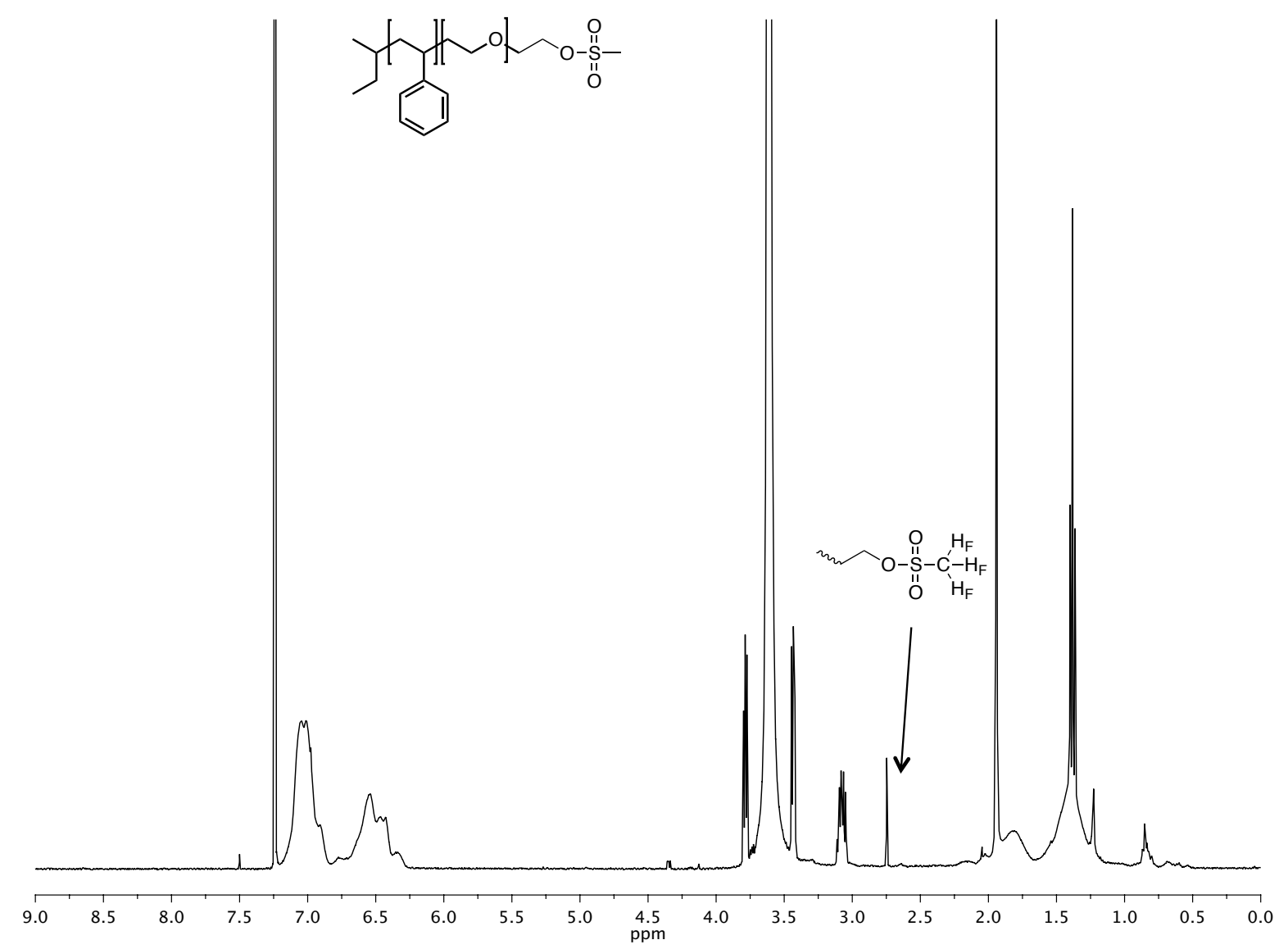

Figure S2. ${ }^{1} \mathrm{H}-\mathrm{NMR}$ spectrum of SO-Ms (methanesulfonyl (mesyl)). This compound is the precursor of SO-azide. 
(3) ${ }^{1} \mathrm{H}-\mathrm{NMR}$ spectrum of SO-azide

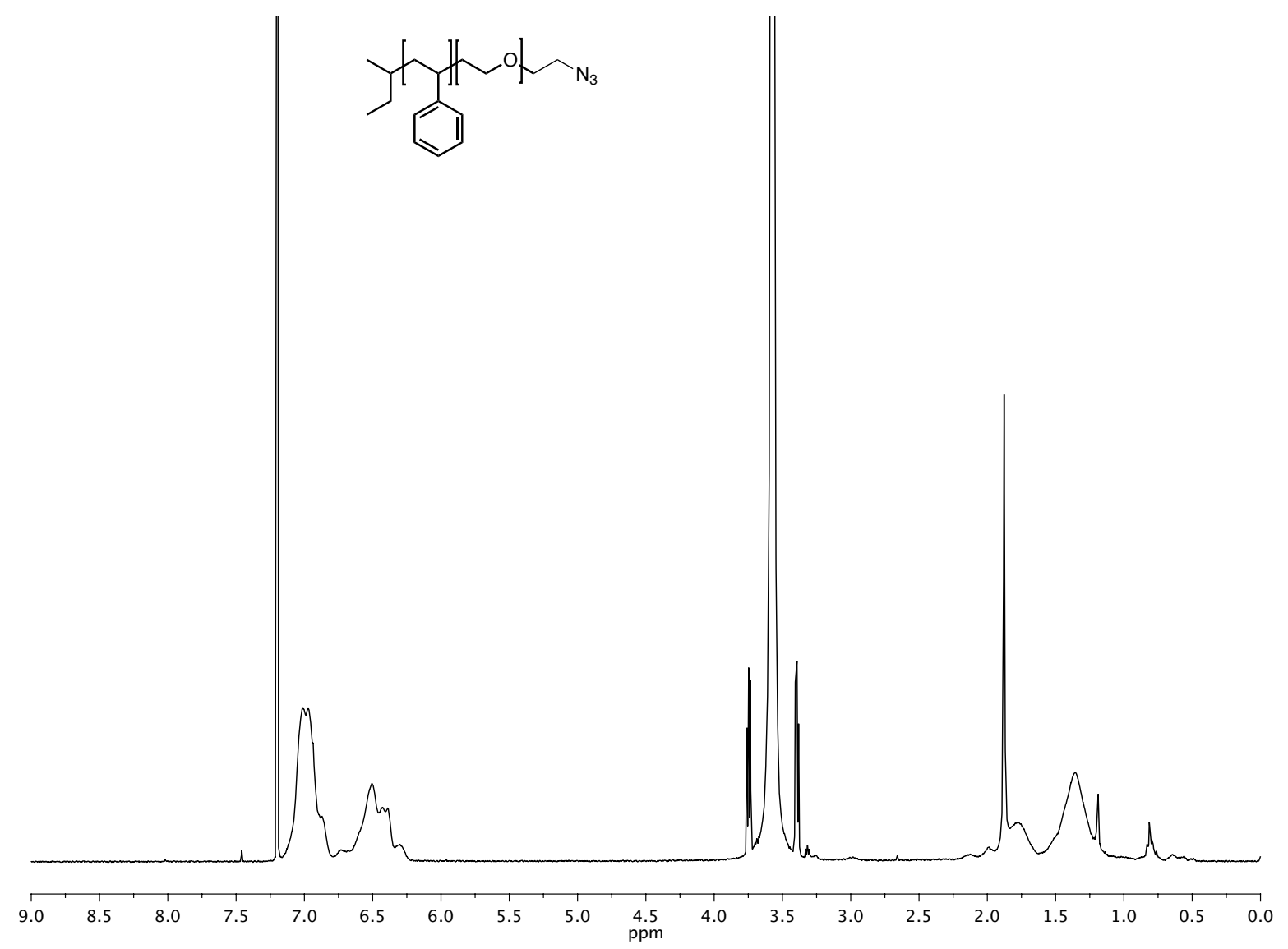

Figure S3. ${ }^{1} \mathrm{H}-\mathrm{NMR}$ spectrum of SO-azide. The terminal methylene protons adjacent to the azide end group overlap with the methylene protons of the PEO backbone (4.0-3.2 ppm). Confirmation of azide group functionality is shown in the FTIR spectrum in Figure S5. 
(4) ${ }^{1} \mathrm{H}-\mathrm{NMR}$ spectrum of SO-alkyne

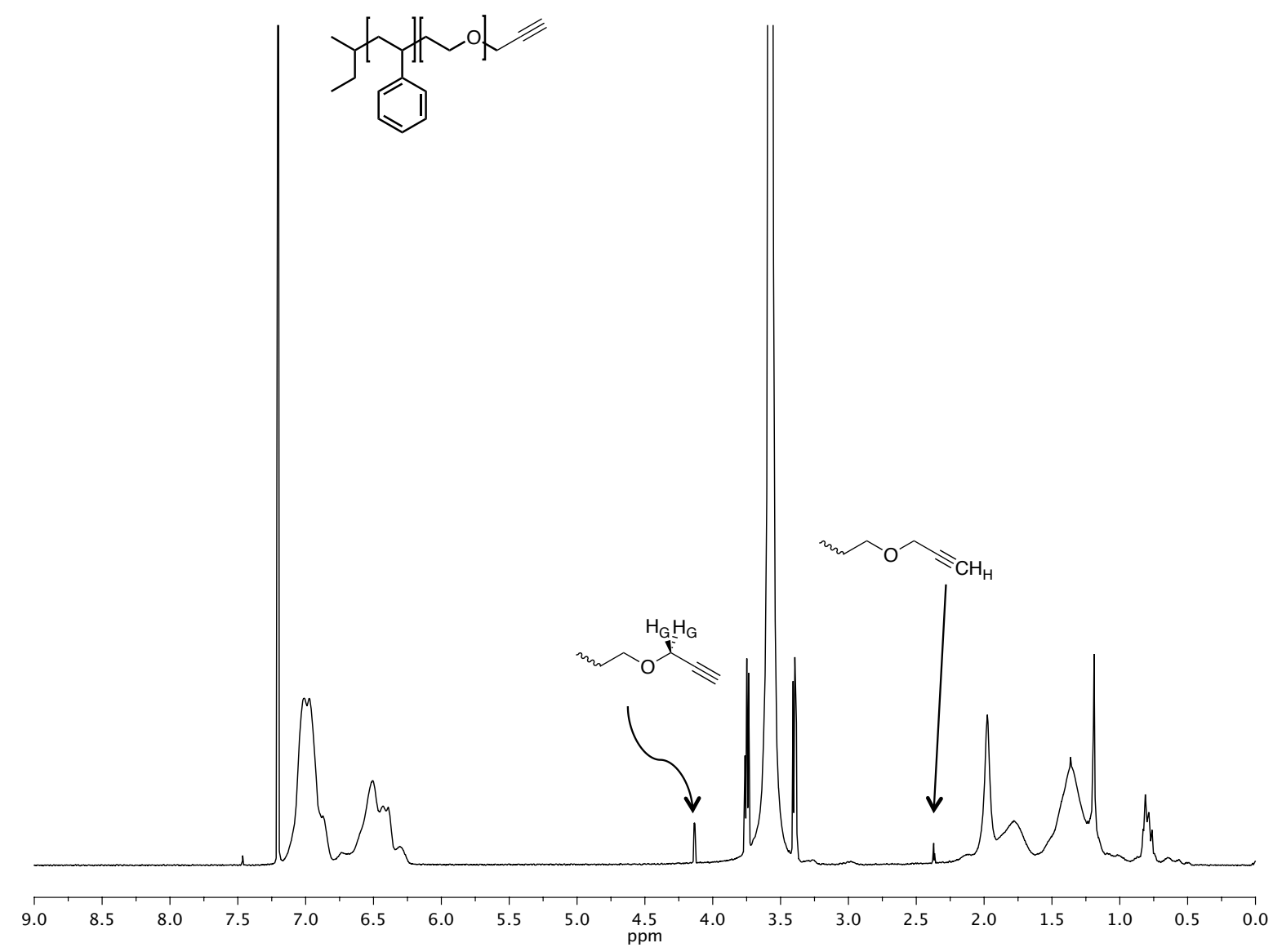

Figure S4. ${ }^{1} \mathrm{H}-\mathrm{NMR}$ spectrum of SO-alkyne. 
(5) FTIR spectrum of SO-azide

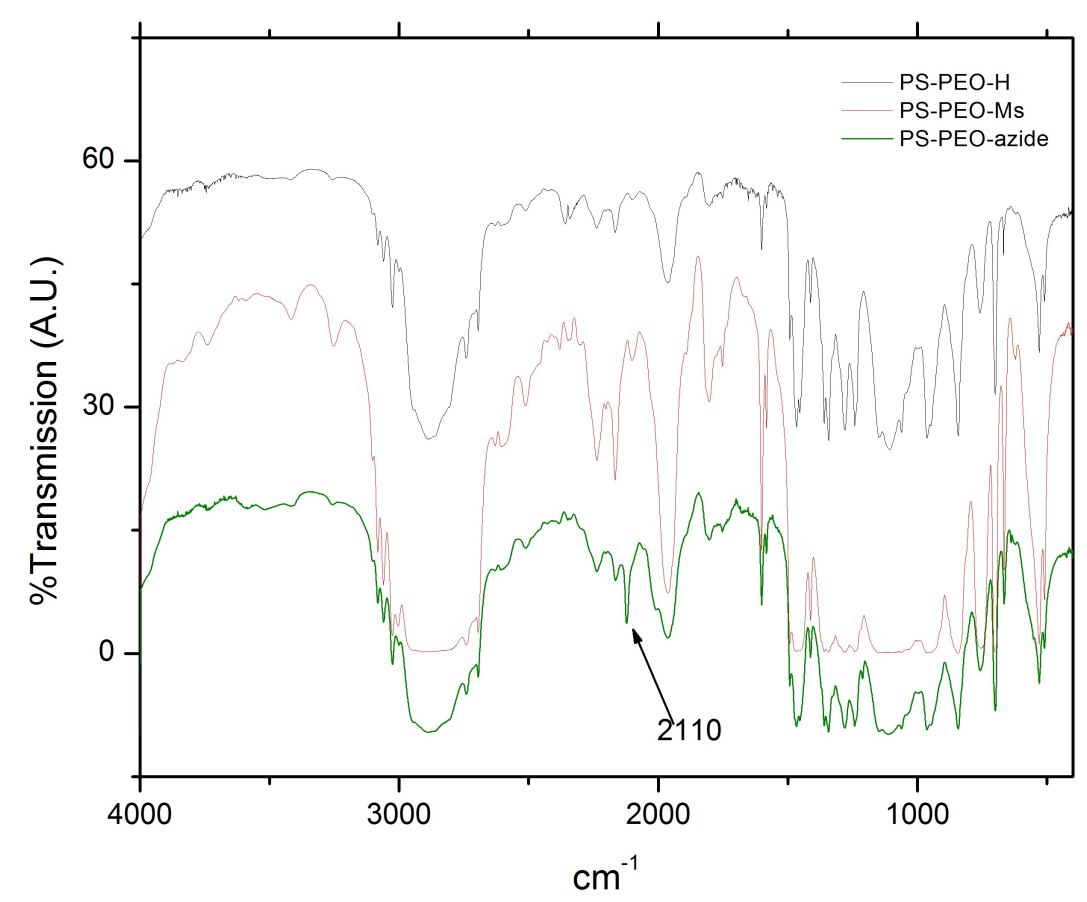

Figure S5. FTIR spectra of SO-H, SO-Ms and SO-azide. The characteristic vibration for the azide group is shown at $2110 \mathrm{~cm}^{-1}$.

(6) SEC overlay of SO-H, SO-Ms, SO-azide, and SO-alkyne

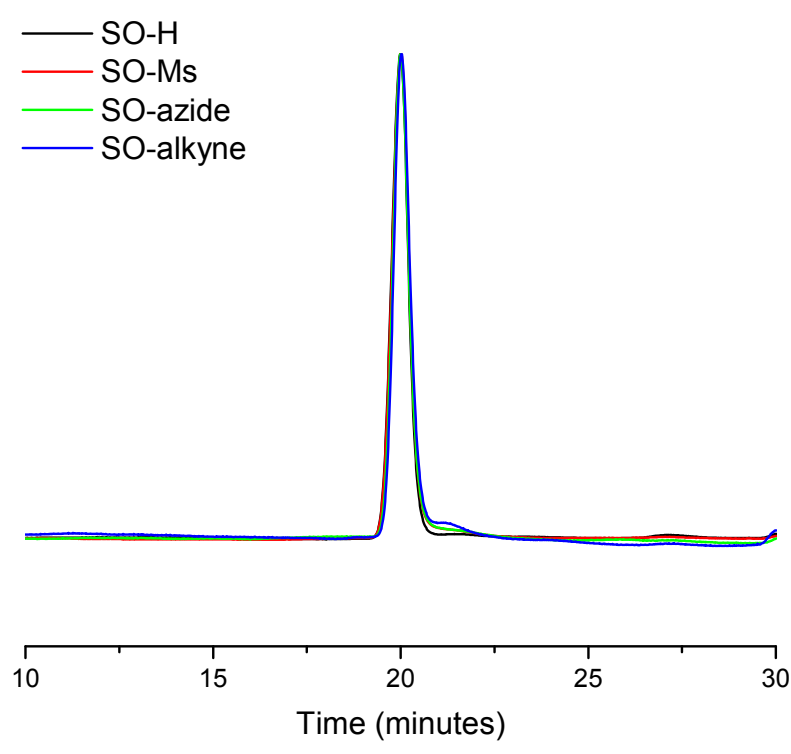

Figure S6. SEC data of functionalized SO diblock copolymer species used in this study. Chemical modification of chain ends had minimal influence on the molecular weight distribution of the original SO-H diblock copolymer precursor. 

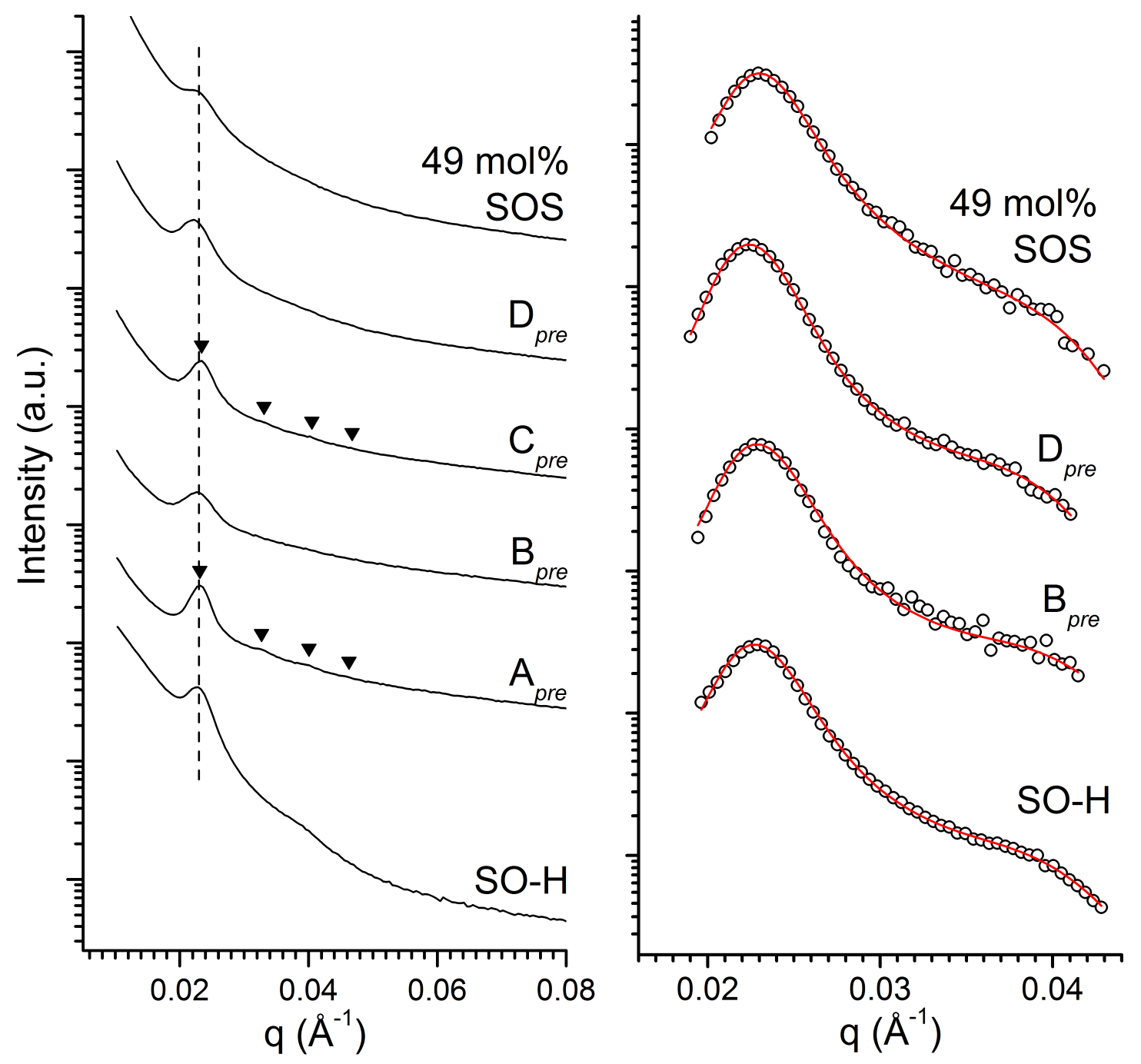

Figure S7. (Left) 1D azimuthally integrated SAXS data for SO-H $\left(100^{\circ} \mathrm{C}\right)$, blends A - D $\left(120^{\circ} \mathrm{C}\right)$, and an SO/SOS baseline blend containing $49 \mathrm{~mol} \% \operatorname{SOS}\left(120^{\circ} \mathrm{C}\right)$. All blends have identical PS volume fractions of 0.13 . At this composition, a BCC lattice is thermodynamically preferred, but systems can take hours to develop such high degrees of order. Above, blends A and C exhibit the early emergence of a BCC lattice after several hours of annealing. Inverted triangles appear at locations where higher order $B C C$ reflections are expected to appear $\left(q / q^{*}=q / q_{110}=\sqrt{2}\right.$, $\sqrt{4}, \sqrt{ } 6, \sqrt{8} \ldots)$. On the other hand, SO-H, 49 mol\% SOS, blend B and blend D are unable to adopt the BCC lattice during the measurement time frame ( $3 \mathrm{hrs}$ ) and a liquid-like packing (LLP) of spherical domains remains. Our experience is that systems at these compositions and overall molecular weights sit right at some kinetic threshold, such that samples can reside in the LLP state for unpredictable periods before the BCC lattice is finally adopted. ${ }^{1,2}$ Regardless, formation of the BCC lattice is unnecessary for efficient network formation, ${ }^{3,4}$ and as the dashed vertical line indicates, each of these systems shares a near coincidence of the principal scattering peak position $\left(\mathrm{q}^{*} \sim\right.$ $0.023 \AA^{-1}$ ) Such similarity is expected based on our previous experience with these types of blends, and is an intended by-product of using "lattice matched" SO-X and SOS block copolymer compositions. ${ }^{3,4}$ Importantly, the addition of small functional groups at the chain ends appears to have no particular influence on the basic selfassembly process in these systems. (Right) In cases were LLP of the spherical domains is found, SAXS data fits to a 
Percus-Yevick (PY) hard sphere model ${ }^{5}$ for polydisperse spheres, as described previously by our group ${ }^{3,4}$ and others $^{6-10}$ can be used to extract structural characteristics of the morphology. Table S1 summarizes the structural characteristics of each of the six samples, from analysis of the BCC lattice in the cases of blends A and C, or from the PY-fits in the cases of SO-H, $49 \mathrm{~mol} \% \mathrm{SOS}$, blend B and blend D. Of note is the nearly constant PS core radius $\left(R_{c}\right)$ and PS chains per spherical aggregate $\left(\theta_{\mathrm{PS}}\right)$.

Table S1. Chemical and melt-state morphological characterization data of block copolymer blends

\begin{tabular}{|c|c|c|c|c|c|c|c|c|c|}
\hline \multirow{2}{*}{ Sample } & \multirow{2}{*}{$\begin{array}{c}\text { SOS } \\
(\mathrm{mol} \%)\end{array}$} & \multirow{2}{*}{$\mathrm{q}^{*}{ }_{110} / \AA^{-1}$} & \multirow{2}{*}{$\mathrm{d}^{*}{ }_{110} / \mathrm{nm}$} & \multirow{2}{*}{$f_{\mathrm{PS}}$} & \multicolumn{5}{|c|}{ BCC Lattice } \\
\hline & & & & & $R_{\mathrm{c}} / \mathrm{nm}$ & & $\theta_{\mathrm{PS}}{ }^{\mathrm{c}}$ & & $a^{f} / \mathrm{nm}$ \\
\hline A & 9.3 & 0.0231 & 27.2 & 0.130 & 9.6 & & 256 & & 38.4 \\
\hline $\mathrm{C}$ & 10.4 & 0.0234 & 26.9 & 0.130 & 9.5 & & 248 & & 38.0 \\
\hline \multirow{2}{*}{ Sample } & SOS & $-* / \Omega^{-1}$ & $d * / n m$ & & \multicolumn{5}{|c|}{ Percus-Yevick hard sphere model } \\
\hline & $(\mathrm{mol} \%)$ & q./A & a & & $R_{\mathrm{c}}^{\mathrm{a}} / \mathrm{nm}$ & $\phi_{\mathrm{c}}^{\mathrm{b}}$ & $\theta_{\mathrm{PS}}{ }^{\mathrm{c}}$ & $R_{\mathrm{hs}}{ }^{\mathrm{d}} / \mathrm{nm}$ & $\phi_{\mathrm{hs}}{ }^{\mathrm{e}}$ \\
\hline $\mathrm{SO}-\mathrm{H}$ & 0.0 & 0.0229 & 27.5 & 0.130 & 9.6 & 0.122 & 255 & 154 & 0.51 \\
\hline $\mathrm{B}$ & 9.8 & 0.0227 & 27.7 & 0.130 & 9.6 & 0.124 & 255 & 154 & 0.52 \\
\hline $\mathrm{D}$ & 8.9 & 0.0222 & 28.3 & 0.130 & 9.6 & 0.118 & 256 & 159 & 0.54 \\
\hline SOS $49 \mathrm{~mol} \%$ & 49.0 & 0.0225 & 28.0 & 0.130 & 9.5 & 0.125 & 250 & 151 & 0.50 \\
\hline
\end{tabular}



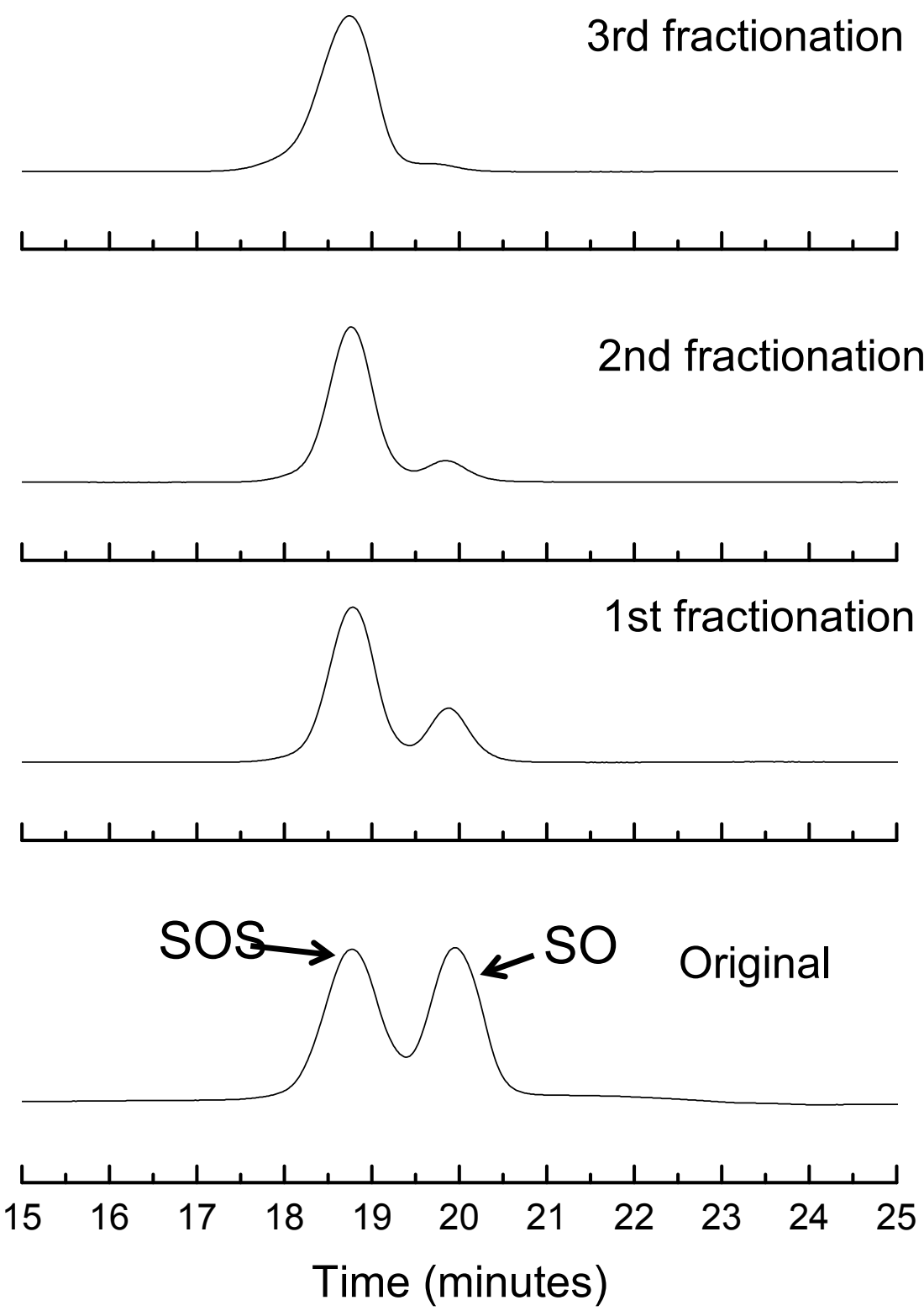

Figure S8. SEC of original dibromoxylene coupling reaction to form a mixture of SO-H diblock copolymer and the desired SOS triblock copolymer. Fractionation was carried out using chloroform/n-hexane as the solvent/nonsolvent pair and a temperature higher than $40{ }^{\circ} \mathrm{C}$ to avoid solution based PEO crystallization. ${ }^{4,11}$ 
(9) SEC comparision of SO-H/SOS blends pre- and post application of the hot press
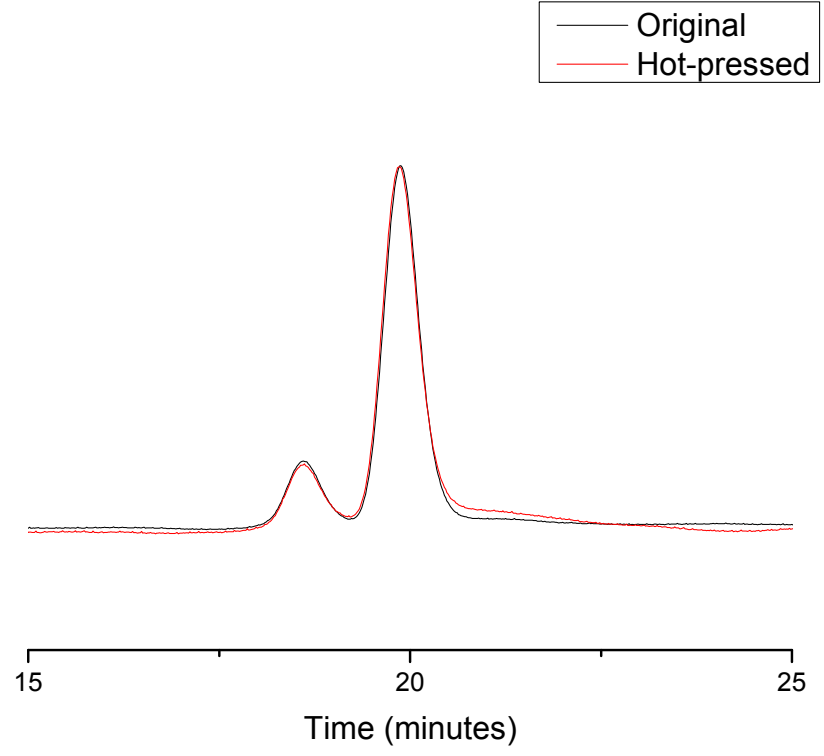

Figure S9. SEC of typical SO-H/SOS blends confirmed the stability of the molecular weight distribution during routine hot pressing of the samples.

(10) Dynamic frequency sweep results (elastic shear moduli) for samples A1 - D1, baseline SO-H/SOS hydrogels of 4.1 and $20.3 \mathrm{~mol} \%$ SOS, and a catalyst control sample.

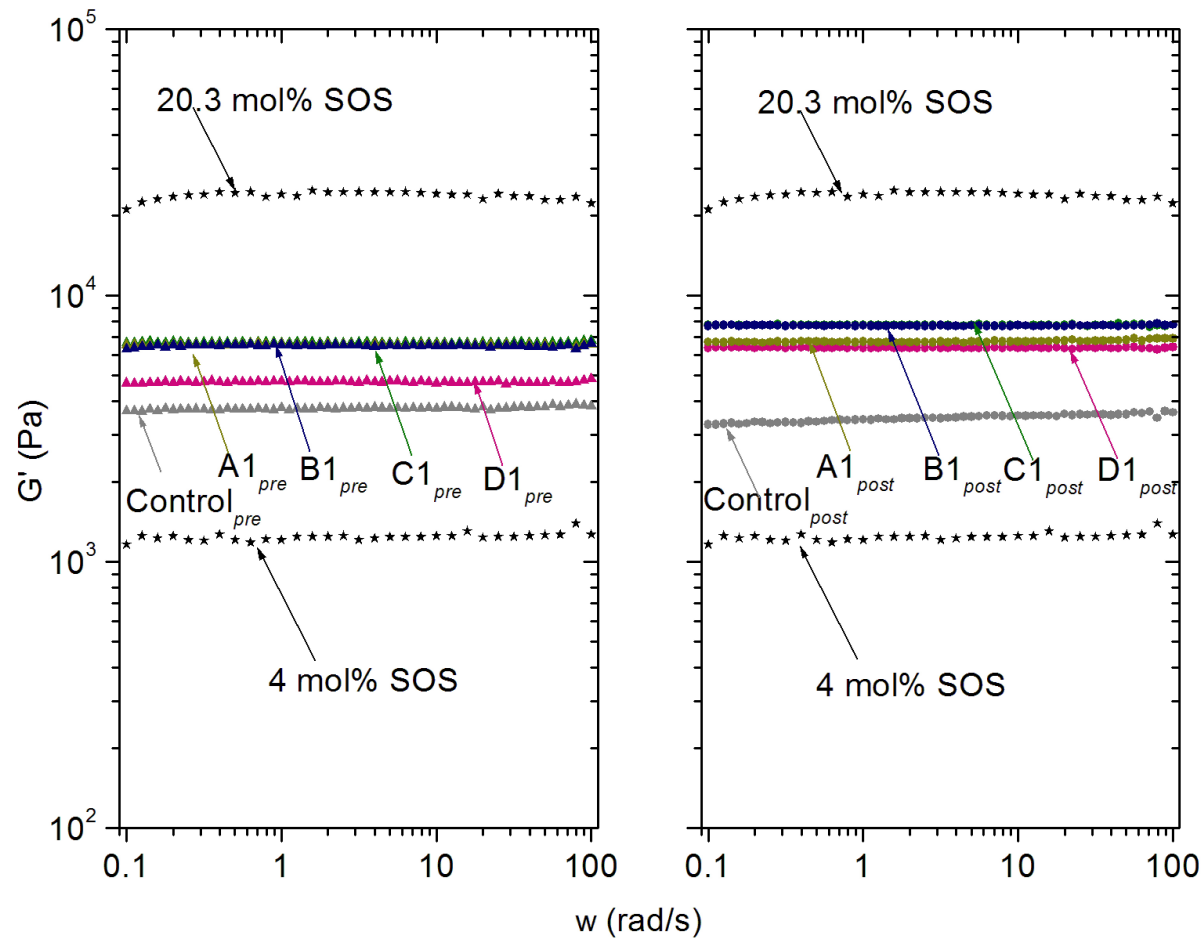

Figure S10. Representative dynamic frequency sweep results showing the elastic moduli for samples A1 - D1, two baseline SO-H/SOS hydrogels of 4.1 and $20.3 \mathrm{~mol} \% \mathrm{SOS}$, and a baseline SO-H/SOS hydrogel soaked in catalyst solution for 24 hours (control). 
(11) Unconfined compression for samples A1 - D1, and a catalyst control sample.

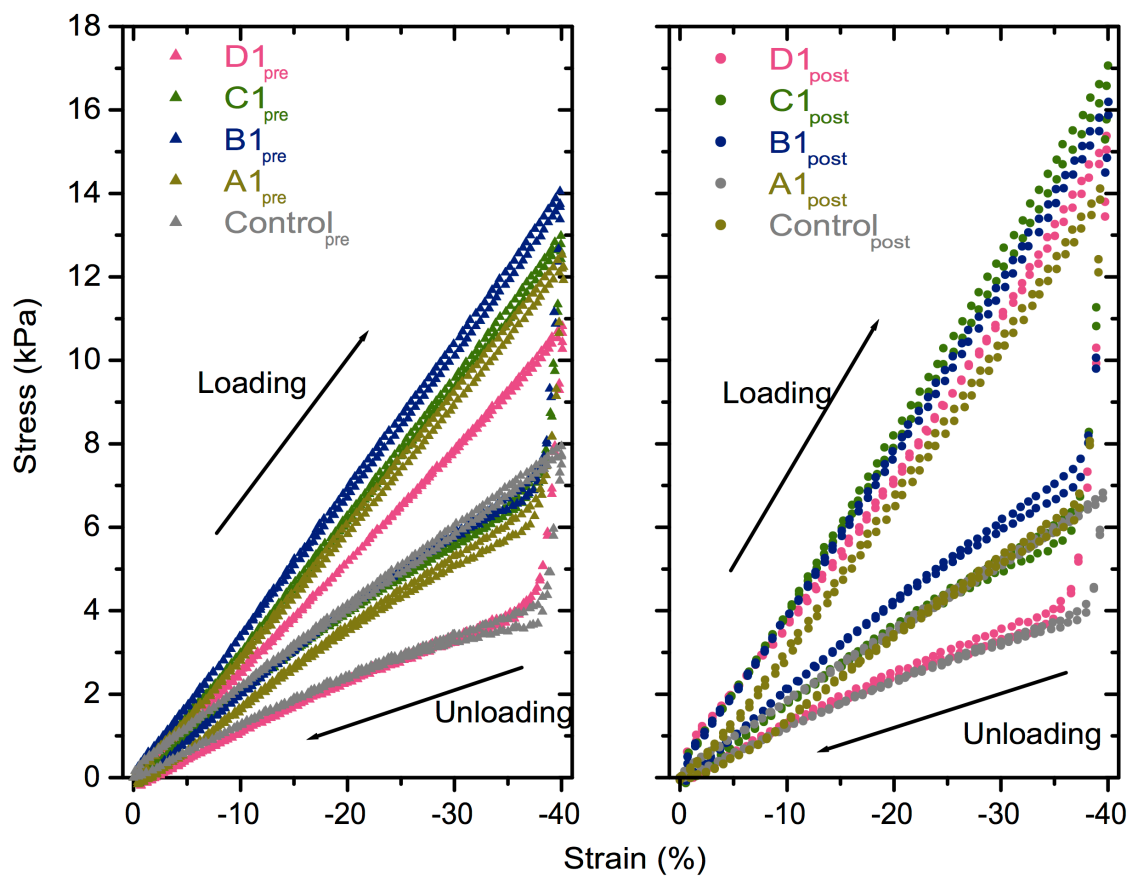

Figure S11. Representative unconfined compression results showing the stress-strain relationships for samples A1 D1, and a baseline SO-H/SOS control hydrogel soaked in catalyst solution for 24 hours (control).

(12) Sample Identification History

\begin{tabular}{|l|l|}
\hline Manuscript ID & Lab Notebook IDs \\
\hline SO & CG3196 \\
\hline SO-Ms & MMS1015 \\
\hline SO-alkyne & JTL1004 \\
\hline SO-azide & JTL1024 \\
\hline Blend A: azide:alkyne:OH=15:15:70 & CG3034D, JTL1040D \\
\hline Blend B: azide:alkyne:OH=25:25:50 & CG3034C, JTL1040C \\
\hline Blend C: azide:alkyne:OH=35:35:20 & CG3034B, JTL1040B \\
\hline Blend D: azide:alkyne:OH=45:45:0 & CG3034A, JTL1040A \\
\hline Baseline 20 mol\% SOS & CG4053A \\
\hline Baseline 30 mol\% SOS & CG4053B \\
\hline Baseline 40 mol\% SOS & CG4053C \\
\hline Baseline 50 mol\% SOS & CG4050 \\
\hline
\end{tabular}

\section{(13) References}

1. Scalfani, V. F.; Bailey, T. S., Access to Nanostructured Hydrogel Networks through Photocured BodyCentered Cubic Block Copolymer Melts. Macromolecules 2011, 44, 6557-6567.

2. Scalfani, V. F.; Wiesenauer, E. F.; Ekblad, J. R.; Edwards, J. P.; Gin, D. L.; Bailey, T. S., Morphological Phase Behavior of Poly(Rtil)-Containing Diblock Copolymer Melts. Macromolecules 2012, 45, 4262-4276.

3. Guo, C.; Bailey, T. S., Highly Distensible Nanostructured Elastic Hydrogels from Ab Diblock and Aba Triblock Copolymer Melt Blends. Soft Matter 2010, 6, 4807-4818. 
4. Guo, C.; Bailey, T. S., Tailoring Mechanical Response through Coronal Layer Overlap in Tethered Micelle Hydrogel Networks. Soft Matter 2015, 11, 7345-7355.

5. Percus, J. K.; Yevick, G. J., Analysis of Classical Statistical Mechanics by Means of Collective Coordinates. Physical Review 1958, 110, 1-13.

6. Dormidontova, E. E.; Lodge, T. P., The Order-Disorder Transition and the Disordered Micelle Regime in Sphere-Forming Block Copolymer Melts. Macromolecules 2001, 34, 9143-9155.

7. Kinning, D. J.; Thomas, E. L., Hard-Sphere Interactions between Spherical Domains in Diblock Copolymers. Macromolecules 1984, 17, 1712-1718.

8. Schwab, M.; Stuhn, B., Thermotropic Transition from a State of Liquid Order to a Macrolattice in Asymmetric Diblock Copolymers. Phys Rev Lett 1996, 76, 924-927.

9. Schwab, M.; Stuhn, B., Asymmetric Diblock Copolymers - Phase Behaviour and Kinetics of Structure Formation. Colloid and Polymer Science 1997, 275, 341-351.

10. Wang, X.; Dormidontova, E. E.; Lodge, T. P., The Order-Disorder Transition and the Disordered Micelle Regime for Poly(Ethylenepropylene-B-Dimethylsiloxane) Spheres. Macromolecules 2002, 35, 9687-9697.

11. Fragouli, P. G.; Iatrou, H.; Hadjichristidis, N., Synthesis and Characterization of Linear Diblock and Triblock Copolymers of 2-Vinyl Pyridine and Ethylene Oxide. Polymer 2002, 43, 7141-7144. 